\title{
VACUUM BASED WIPING SYSTEM FOR POLLEN AND DUST FREE SURFACES - IN A CASE STUDY WITH BLACKBOARD
}

\author{
Krithika P, M Sirisha, Srividya V R, Sushmitha K N \\ Department of Electronics and Communication \\ KS Institute of Technology, Bangalore, Karnataka, India
}

\begin{abstract}
Due to the sharp growth in technologies, humans demand high-performance machines to perform their tasks to make their life a bit effortless. This wiping system is made to ease the monotonous job of erasing blackboards by teachers. In this paper, a roller wiper is used that is rested upon the blackboard and it moves in line with the split-up made in blackboard using a DC motor and collects the dust spontaneously using a vacuum cleaner. To push and pull the roller wiper a servomotor is accustomed, and the position of the wiper is automated by an Arduino. Thus, it eludes the dust flow to the atmosphere thereby averting health issues triggered by dust and keeping the environment clean.
\end{abstract}

Keywords-Dust management, roller wiper, microcontroller

\section{INTRODUCTION}

India is a progressing country that immensely uses domestic methods in the field of education. Most of the schools in India still use blackboards as a mode of supervising.

Blackboards are the foundation in classrooms for constructive teaching and learning purposes where chalk pieces are used to write on the board. This chalk piece is a soft, form of limestone that generates chalk dust which leads to many health issues for humans and produces harmful effects to the apparatus in the classroom. It involves irritation and allergies to skin, tissues, eyes, and during inhaling it leads to problems related to the respiratory system, and when imbibed by the skull it induces severe hair loss and all of these remain a major concern during the pandemic.

The classroom turns out untidy with those bags of dust. Though dust-free chalk pieces are being modeled, they produce few amounts of chalk dust comparatively lower than normal chalk pieces but still, there are chances for the dust assemblage.

Furthermore, chalk dusts not only cripple the human but also the equipment. Instruments that are used in the classrooms like projectors when subjected to the chalk dust which is not heavy get easily landed on the instrument. This is one of the causes of heat production in the instruments.

When a large amount of heat is produced the instrument may deteriorate before its effective life span ends.
Hence the Arduino-based smart blackboard erasing system proposed in this paper can be used to eschew the above problems and to decrease the manual work.

\section{LITERATURE SURVEY}

Ancient blackboard erasers were primarily wet clothes or timber adhered with eraser materials.

They were potent but made the user open to the chalk dust which may not be deadly but could cause allergies and problems to individuals infected by asthma or any other breathing complications. The basic framework always included the blackboard itself as a critical part as well as the duster placed in different modes but with a single aim to erase the blackboard. The most developed blackboard model was designed by Jinzan Liu, Zhong Zeng \& Lang Xu [2]. This blackboard erasing arrangement was the most advanced blackboard erasing system which used cameras and digital image processing to erase the erasable markings present on the blackboard.

In 2002 Chirag Shah [4] strived to make the blackboard structure with sensors attached to the motors to actuate motor movement. The technique to control switches was with the user. The duster moved back and forth to erase the blackboard. Once the motor starts moving the gear and counter gear connected to the threaded rod which then moves the shaft.

Billie R. Crisp [8] designed a system in 1971, automatic dust erasing tool for classroom use. The motion of the shaft fixed with the eraser was primarily done by manual switches.

In 1993 Solomon Forst [12] proposed a blackboard erasing arrangement. The blackboard is installed with the cleaning device fitted to the wall which includes a separate duster tool rather than the cleaning material which was used in the earlier models.

\section{PROBLEM IDENTIFICATION}

- Dust management and other health-related issues

- Time-consuming and inflexible

- Domestic manual mode of operation 


\section{International Journal of Engineering Applied Sciences and Technology, 2021 \\ Vol. 5, Issue 12, ISSN No. 2455-2143, Pages 231-232 \\ Published Online April 2021 in IJEAST (http://www.ijeast.com)}

\section{OBJECTIVES}

A safety sound device is used to wipe out the blackboard automatically. It truncates the time utilization and complexities, unlike the old domestic procedure.

Avoids dust flow to the environment thus pre-empting health issues and helps to keep the surroundings unstained. Much quicker than the prevailing approaches and provides numerous useful options.

Affordable at nominal costs compared to smart boards.

\section{V.BLOCK DIAGRAM}

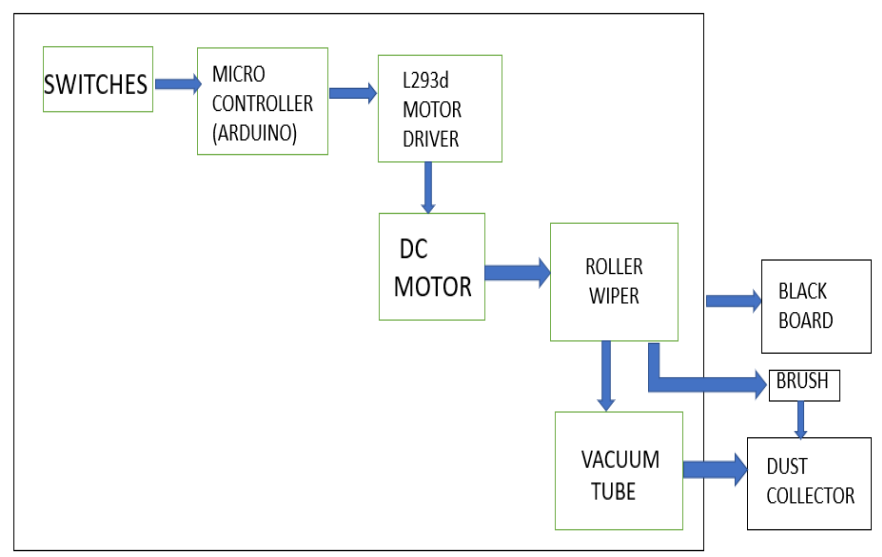

Fig. Block diagram for vacuum-based wiping system

The above figure shows the entire setup of the control unit which consists of pair of switches, micro-controller, a motor driver and a roller wiper which is connected to the blackboard. The roller wiper is additionally provided with the brush at the bottom which eliminates additional minute dust particles fallen on the surface while erasing.

\section{EXPERIMENT AND RESULT}

- The arrangement consists of a DC motor, guide rails, roller, vacuum cleaner, and an Arduino board microcontroller.

- The DC motor is used to shift the roller wiper to erase the split-up portion of the blackboard run by the switches.

- A vacuum cleaner affixed to the bottom of the roller is used to suck the dust particles.

- Arduino board microcontroller controls the entire operation of the system.

- This whole mechanism can be done in two different viewpoints namely,

1. Wipe and dust full board

2. Wipe and dust half the board

\section{CONCLUSION}

This proposal is a wanted solution for the schools yet using traditional blackboards as they prove to be effective in time used for dusting boards and also will get protected from the dust ejected from it thereby from allergies or pollen which affect the lungs. Hence by using digital image processing, an automatic board wiper can be designed which wipes only where content is there. This reduces time and increases flexibility.

\section{REFERENCE}

[1] Rubhini B, Mrunalini T, (August 2014), "Real-Time Automated Blackboard Eraser Using Embedded System", in IJIRSET, (vol 3, issue 8).

[2] Jinzan Liu, Zhong Zeng1 \& Lang Xu, (2013), "The New Smart Eraser Design", in Modern Applied Science; Vol. 7, No. 2.

[3] PRAVEEN.G,(8thSept.2013), "MICROCONTROLLER BASED AUTOMATIC ELECTRONICDUSTER", in Proceedings of An International Academic Conference on Electrical, Electronics and Computer Engineering.

[4] Chirag Shah, (2005) 'Automated Board Eraser', Patent US 6,948,210 B1.

[5] Puneet Mathur, Bhushan Tukaram Chougule, Ravina Nangare,"(2013), “Automated Motorized Whiteboard", in International Journal of Engineering, Business and Enterprise Applications (IJEBEA).

[6] X. Mercilin Raajini1, G. Rajesh2, V.P. Arun Pandian3, N. Vengadesh4, (August 2018), "ARDUINO BASED SMART BLACKBOARD WIPING SYSTEM", in JCRES, (volume -1 issue-1).

[7] Mr. Sunil R. Kewate, Mr. Inzamam T. Mujawar, Mr. Akash D. Kewate, Mr. Hitesh R. Pant, "Development of New Smart Design to Erase the Classroom Blackboard of Schools/Colleges", in IOSR Journal of Mechanical and Civil Engineering (IOSR-JMCE), eISSN: 2278-1684, p-ISSN: 2320-334X, PP 57-61.

[8] Billie R. Chrisp, (1973) 'Automatic Chalkboard Erasing Apparatus', Patent 3731335.

[9] Rolland L. Schlik, (1975) 'Automatic Blackboard Eraser', Patent US3858265 A.

[10] Yu-Hsuan Liu, (2004) 'Structure of a Multifunctional Board Eraser', US6793430.

[11] Bell John W, (patent, 1962) "Mechanical blackboard eraser", US 3163943 A.

[12] Solomon Forst, (1993) 'Apparatus for Cleaning Blackboards', Patent US531980.

[13] Chirag Shah, (2005) 'Automated Board Eraser', Patent US 6,948,210 B1.

[14] Vivek D. Ugale, Aishwarya Marathe, Tiwari Ashutosh, Nilesh Ugale, (April 2015) "AUTOMATIC BLACKBOARD ERASER", in International Journal of Advanced Research in Electronics and Communication Engineering (IJARECE), (Volume 4, Issue 4). 